\title{
The Treatment of Angiotensin-converting Enzyme Inhibitors in Coronavirus Disease 2019 Patients with Hypertension: A Narrative Review
}

Mohammad Rudiansyah $^{1 *}$ (D) , Haryati Haryati ${ }^{2}$ D, Enita Rakhmawati Kurniaatmaja ${ }^{1}$ (D) Nanik Tri Wulandari ${ }^{1}$ (D) Lily Runtuwene ${ }^{3}$, Aqsha Tiara Viazelda ${ }^{4}$ (i), Mohammad Agung Raihan Rudiansyah ${ }^{5}$ (D)

${ }^{1}$ Department of Internal Medicine, Division of Nephrology and Hypertension, Faculty of Medicine, Universitas Lambung Mangkurat, Ulin Hospital Banjarmasin, Indonesia; ${ }^{2}$ Department of Pulmonology and Respiratory Medicine, Faculty of Medicine, Universitas Lambung Mangkurat, Ulin Hospital Banjarmasin, Indonesia; ${ }^{3}$ Department of Neurology, Faculty of Medicine, Universitas Lambung Mangkurat, Ulin Hospital Banjarmasin, Indonesia; ${ }^{4}$ Department of Internal Medicine, Internal Medicine Residency Program, Department of Internal Medicine, Faculty of Medicine, Universitas Lambung Mangkurat, Ulin Hospital Banjarmasin, Indonesia; ${ }^{5}$ Medical Education Study Program, Faculty of Medicine, Universitas Lambung Mangkurat, Ulin Hospital Banjarmasin, Indonesia

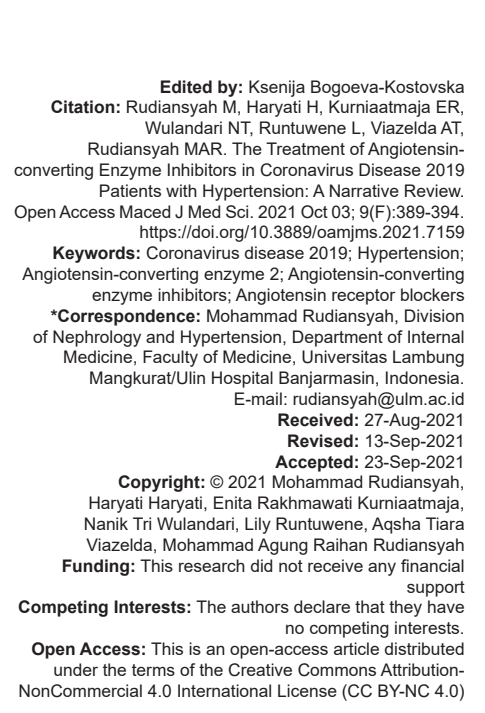

\begin{abstract}
A new strain of the severe acute respiratory syndrome coronavirus 2 (SARS-CoV-2) induces coronavirus disease 2019 (COVID-19), a contagious respiratory disorder resulting in illness. Meanwhile, the World Health Organization classified this virus as a pandemic due to its rapid transmission and daily growing fatality rates. The condition is commonly manifested as clinical symptoms such as fever, cough, shortness of breath, and cardiovascular disease. Although there is a high probability of COVID-19 patients developing cardiovascular problems, such as hypertension, there is no established causative association between both conditions. In general, this type of comorbidity is extremely common in the elderly, which increases their risk of infection with the SARS-CoV-2 virus. The Internationa Society of Hypertension issued the most recent guidelines for the treatment and management of hypertension in 2020, of which the most employed are angiotensin-converting enzyme inhibitors (ACE-i) and angiotensin receptor blockers (ARB). Therefore, this research aims to investigate the treatment of ACE-i/ARB in hypertensive individuals with COVID-19. The reason is that there have been some concerns expressed about the usage of these medications due to their influence on angiotensin-converting enzyme 2 (ACE2), which is the entrance site for SARS-CoV-2, particularly in the lungs. Subsequently, the results showed that discontinuing ACE-i/ARB is not advised, especially during the pandemic. This is based on data comparing mortality rates between participants on ACE-i/ARB and those not on ACE-i/ARB using cases and guidelines for managing hypertension during the pandemic.
\end{abstract}

\section{Introduction}

Severe acute respiratory syndrome coronavirus 2 (SARS-CoV-2) is a viral pathogen that induces respiratory tract illnesses, and it is also known as coronavirus disease 2019 (COVID-19). This virus was initially identified in Wuhan, China, and 200 countries suffer within a few months. Furthermore, it infects the respiratory system and spreads swiftly through droplets and direct contact [1]. Therefore, the World Health Organization (WHO) labeled it a global pandemic, most notably for its rapid spread.

The first incidence of the virus in Indonesia was discovered in early March 2020. Recently, the number of cases continually increases by the day [2]. Consequently,
Indonesia is at a high risk of disease prevalence and rapidly growing mortality and morbidity rates.

COVID-19 disease is worsened by comorbidities, making it easier for the virus to damage the body. One of the most common morbidities that interact with this virus is hypertension [3]. Several research have shown a two-fold increase in the death rates of hypertensive patients with COVID-19 [4]. This is because this illness is very common among the elderly, who are also at a higher risk of contracting the SARS-CoV-2 virus. Although it remains unknown whether hypertension is a risk factor for the virus, blood pressure control remains an important consideration in reducing burdens associated with the disease.

Hypertension management is continuously developed, with various guidance options from 


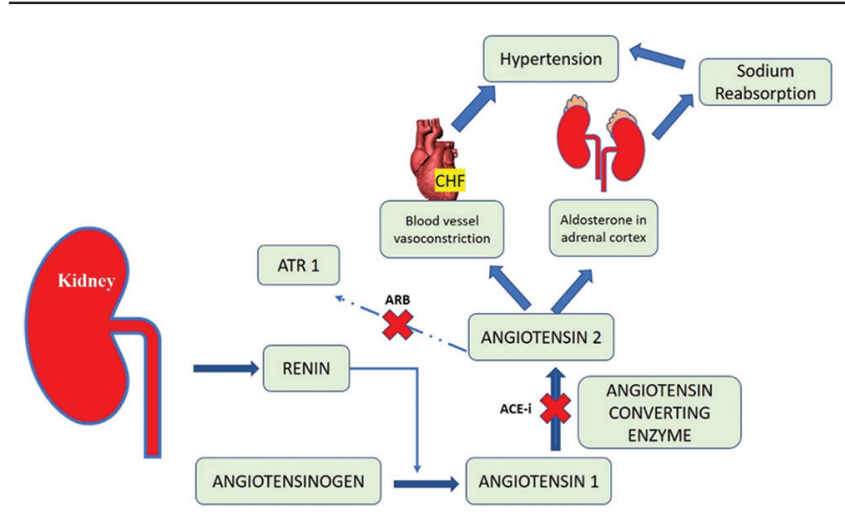

Figure 1: Pathophysiology Interaction of the Renin-Angiotensin Aldosterone System with Cardiac and Kidney Disorders. $\mathrm{CHF}=$ Congestive heart failure, ACE- $i=$ Angiotensin-converting enzyme inhibitor, $A R B=$ Angiotensin II receptor blocker, ATR $1=$ Angiotensin I receptor

numerous agencies or clinician/professional associations. For example, the International Society of Hypertension issued new guidelines for assessing hypertension management in 2020. According to these guidelines, diagnosis is made when a person's systolic blood pressure is about $140 \mathrm{~mm} \mathrm{Hg}$ or higher as well as diastolic blood pressure of $90 \mathrm{~mm} \mathrm{Hg}$ or higher, with repeated examinations [5]. Individuals are more likely to have hypertension if their blood pressure is measured at $140 / 90$ or higher after 2-3 times. The term "normal high blood pressure" was established to characterize individuals who are likely to benefit from lifestyle interventions with pharmacological treatment, assuming the indication for hypertension is strong. Angiotensin-converting enzyme inhibitors (ACE-i) remains the first line of pharmacological therapy in hypertensive patients with various comorbidities. Conversely, Angiotensin Il angiotensin receptor blockers (ARB) blocks the actions of the enzyme angiotensin II in patients, and it is used in patients who can not tolerate ACE-i therapy. This could be due to an ACE-i-induced cough or angioneurotic edema, in which case ARB therapy would be more appropriate and recommended as an alternative.

\section{Hypertension}

Hypertension is the most prevalent and important risk factor for atherosclerotic cardiovascular disease, and it is correlated with complications of the microvasculature. This disease affects about 1.4 billion people worldwide, with most cases reported in low- and middle-income countries [6]. According to global data, one out of every four men and five women suffers from chronic hypertension, which causes huge death of death worldwide. Furthermore, more than 7.8 million people die from this disease each year, and approximately 140,000 million people suffer from hypertension-related disorders caused by an increase in systolic pressure $>140 \mathrm{mmHg}$ [7].

The organs of the body that are closely associated with hypertension are the kidneys and the heart. In general, the kidneys require a good blood circulation system in filtering electrolytes and maintaining a balance of body fluids, performed by the renin-angiotensin-aldosterone system (RAAS). The kidneys and aids secrete renin in converting Angiotensinogen to Angiotensin $\mid$ and then to Angiotensin II. These enzymes elevate blood pressure by causing vasoconstriction of blood vessels in the heart and interfering with Aldosterone produced by the adrenal glands in the renal cortex to increase salt reabsorption (Figure 1).

High blood pressure makes it difficult to flow through small vessels, preventing kidney cells from receiving enough oxygen to function properly. This disrupts blood flow to the heart and kidneys, resulting in a decline in kidney function until the kidneys no longer function. Therefore, the use of antihypertensives, such as ACE-i and ARB, can block the action of angiotensin and help control blood pressure. In various research, ACE-i/ARBs in patients with a history of myocardial infarction and heart failure have been shown to reduce mortality compared to placebo [8], [9].

\section{Use of ACE-I and ARB in COVID-19}

Clinicians and researchers have conducted extensive research on ACE-i and ARB in hypertensive patients with COVID-19. Based on these findings, it is known that coronaviruses use ACE2, a membranebound aminopeptidase widely exposed in the lung, heart, and vascular tissue, as a functional receptor for cell infiltration [10].

ACE-i inhibits angiotensin I to II conversion by ACE, preventing Angiotensin II from binding to Angiotensin I and 2 Receptors (ATR 1 and ATR 2). ATR 1 constricts smooth muscle blood vessels and increases aldosterone levels, resulting in salt reabsorption in the tubules [7], [11]. Therefore, ARBs inhibit ATR 1 and lower the blood pressure through the renin-angiotensin system (RAS), as shown in Figure 2.

Theories on the association between increased ACE2 expression with $A C E-i / A R B$ and the risk of SARS-CoV-2 infection or the severity of COVID19 are still debated. However, several reports indicate that the discontinuation of ACE-i/ARB drugs in patients increases the risk of complications and death [7]. 


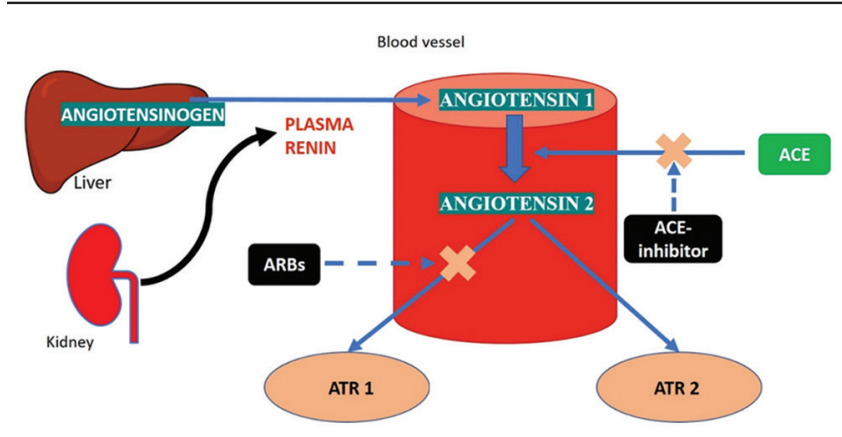

Figure 2: Diagram of the renin-angiotensin system (RAS) and the action and site of movement of the effects of ACE and Angiotensin II receptor inhibitors (ARBs) in blood vessels. ACE=Angiotensinconverting enzyme, ARBs=Angiotensin II receptor blockers, ATR 1=Angiotensin I receptor I, ATR 2=Angiotensin II receptor

\section{Hypertension and use of ACE inhibitors in COVID-19}

ACE2 is a significant RAS segment secreted in the lungs, particularly on the surface of type 2 alveolar epithelial cells. Other areas where this enzyme can be expressed include the upper esophagus, enterocytes in the terminal part of the small intestine (ileum) as well as the colon (large intestine), epithelial cells in the bile, cardiac muscle, proximal tubular cells of the kidney, and urothelial cells in the bladder [12]. The enzyme ACE2 also functions as a SARS-CoV-2 receptor to enter host cells and previously reported SARS-CoV. The affinity of SARSCoV-2 for ACE2 is 10-20 times greater than that of SARS$\mathrm{CoV}$, explaining its greater transmissibility. The excited or spike protein is bound to ACE2 with the help of the enzyme Transmembrane Protease Serine 2 (TMPRSS2), making it easier for the virus to enter, replicate, and transmit between cells [6], [13]. Furthermore, TMPRSS2 and human airway trypsin-like protease can cleave and activate the SARSCoV spike protein (S) for membrane fusion [14]. These proteases can also cleave the viral receptor from the carboxypeptidase ACE2, which increases viral infectivity. In addition, the binding of ACE2 contributes to viral invasion because it collaborates with TMPRSS2 to aid viral entry. TMPRSS2 was found to compete with the metalloprotease ADAMTS17 (a disintegrin and metalloproteinase with thrombospondin motifs, 17) for ACE2 processing, but cleavage by TMPRSS2 occurred in augmented SARSS-driven entry. Also, ADAMTS17 reduces viral activity by preventing TMPRSS2 from binding to ACE2 and making ACE2 more soluble, as shown in Figure 3.

ACE2 is an essential element that counters the regulatory function of the RAS. It is approximately $60 \%$ similar in structure to ACE and binds to the Mas receptor in converting angiotensin II (Ang II) to Ang(1- 7). The Mas receptor is shown on various cell lineages in several cardiovascular disease-relevant tissues, such as type 2 alveolar epithelial cells [15]. Furthermore, ACE decreases blood pressure slightly through vasodilation, stimulation of sodium and water excretion in the kidneys, and attenuation of inflammation through nitric oxide production. This effect is the direct opposite of the conversion by ACE to Ang II in which it acts on the angiotensin type 1 receptor (ATR1) to raise blood pressure by inducing vasoconstriction, enhancing sodium and water reabsorption by the kidneys, as well as oxidative stress, inflammation and fibrosis [15].

ACE-i works by preventing angiotensin 1 from being converted to angiotensin 2 , which is a powerful vasoconstrictor. Inhibition of angiotensin 2 causes blood vessels to dilate and also decreases aldosterone secretion. Therefore, ACE-i plays an essential function in the RAS in maintaining kidney and heart function [15]. The elements of both RAS pathways are found in most human tissues and organ systems. Also, they have paracrine and autocrine functions. The balance between these pathways discovers the ability of tissue injury to occur in response to a stimulus, particularly in the heart and kidneys [16], [17].

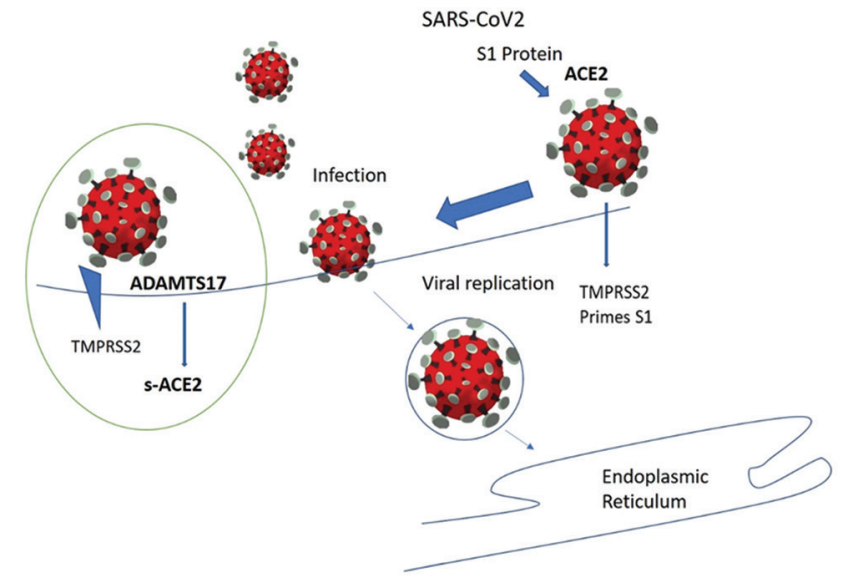

Figure 3: ACE2 works in binding to viral invasion, with TMPRSS2 assisting virus input through ACE2. ADAMTS17 helps reduce viral activity by blocking the binding of TMPRSS2 to ACE2 and making ACE2 more soluble. S1 protein=Virus Spike Protein, SARS-CoV-2=Severe acute respiratory syndrome corona virus 2, ACE2=Angiotensin- converting enzyme 2, TMPRSS2=Transmembrane protease serine 2, ADAMTS17=ADAM metallopeptidase with thrombospondin type 1 motif 17, s-ACE2=Soluble Angiotensin-converting enzyme 2

Juxtaglomerular afferent arteriolar cells synthesize a protein that aids in the action of renin, which converts angiotensinogen produced by the liver into Ang I. Furthermore, ACE converts the Ang I molecule to Ang II, which causes vasoconstriction and increases blood pressure resulting in hypertension. Ang II also stimulates the adrenal cortex and pituitary gland, leading to Aldosterone and anti-diuretic hormone (ADH). Subsequently, Aldosterone stimulates sodium, chloride, and water reabsorption but excretes potassium via the activity of internal mineralocorticoid receptors. Conversely, ADH stimulates the synthesis of aquaporin-2 channels in the collecting duct, thereby increasing water reabsorption. This interaction between ANG II and Aldosterone has the potential to aggravate heart function. ACE-I can prevent this by reducing ANG II and Aldosterone activity, as shown in Figure 4.

The rapid and progressive spread of the 
pandemic has influenced the health of thousands of people, strained national healthcare systems, and had a significant impact on worldwide economic security. In addition, the higher rate of SARS-CoV-2 transmission associated with a higher risk of death, particularly due to acute respiratory distress syndrome, distinguishes this disease from influenza (ARDS). According to preliminary research, respiratory failure is the leading cause of death from COVID-19, especially in the elderly and those with endangered immune systems. Many of these patients have cardiovascular pathologies, such as congestive heart failure and cardiorespiratory medullary heart dysfunction. Cardiovascular complications and the focus on ACE2 as a co-receptor for SARS-CoV-2 and the association of ACE and ACE2 elements of the RAAS with SARS-CoV-2 have stimulated current perspectives on drug use certain cardiovascular events during the pandemic [18].

\section{The Entry of SARS-CoV-2}

Two hypotheses were developed concerning the use of ACE-i and ARB hypertension drugs during the pandemic. The first hypothesis proposed that improved activity of ACE-Ang II compared to ACE2Ang-(1-7) caused acute lung injury in SARS-CoV-2 and COVID-19 cases since SARS-CoV-2 enters cells by binding to ACE2, as shown in Figure 3. Therefore, the addition of ACE-i or ARB increases ACE2 and a concomitant increase in viral entry. This raises questions about using ACE-i and ARBs, prescribed to millions of patients globally, since they may enhance the risk of more severe SARS-CoV-2 COVID-19 infections due to the ACE2 function [19].

\section{ACE-I and ARB Reduce Lung Injury}

The second hypothesis of this study demonstrated that ACE-I and ARB administration reduces the risk of Ang II-mediated acute lung injury by blocking ATR1, which also reduces inflammation and pulmonary fibrosis [15].

According to the most recent data and research on the COVID-19 pandemic, ACE2 levels are a double-edged sword since the enhanced expression of ACE2 facilitates infection and increases the risk of developing severe and fatal symptoms. However, reduced ACE2 expression caused pulmonary edema and decreased lung function, which can be treated with recombinant ACE2 or losartan. Therefore, higher ACE2 expression protects against acute lung injury [20]. However, many public health clinicians advise hypertensive patients to continue taking ACE inhibitors, ARBs, or other reninangiotensin- aldosterone antagonists [21].

ACE-i and ARBs are used to treat hypertension, CKD, proteinuria, and heart failure [11]. Meanwhile, the consequences of stopping these medications

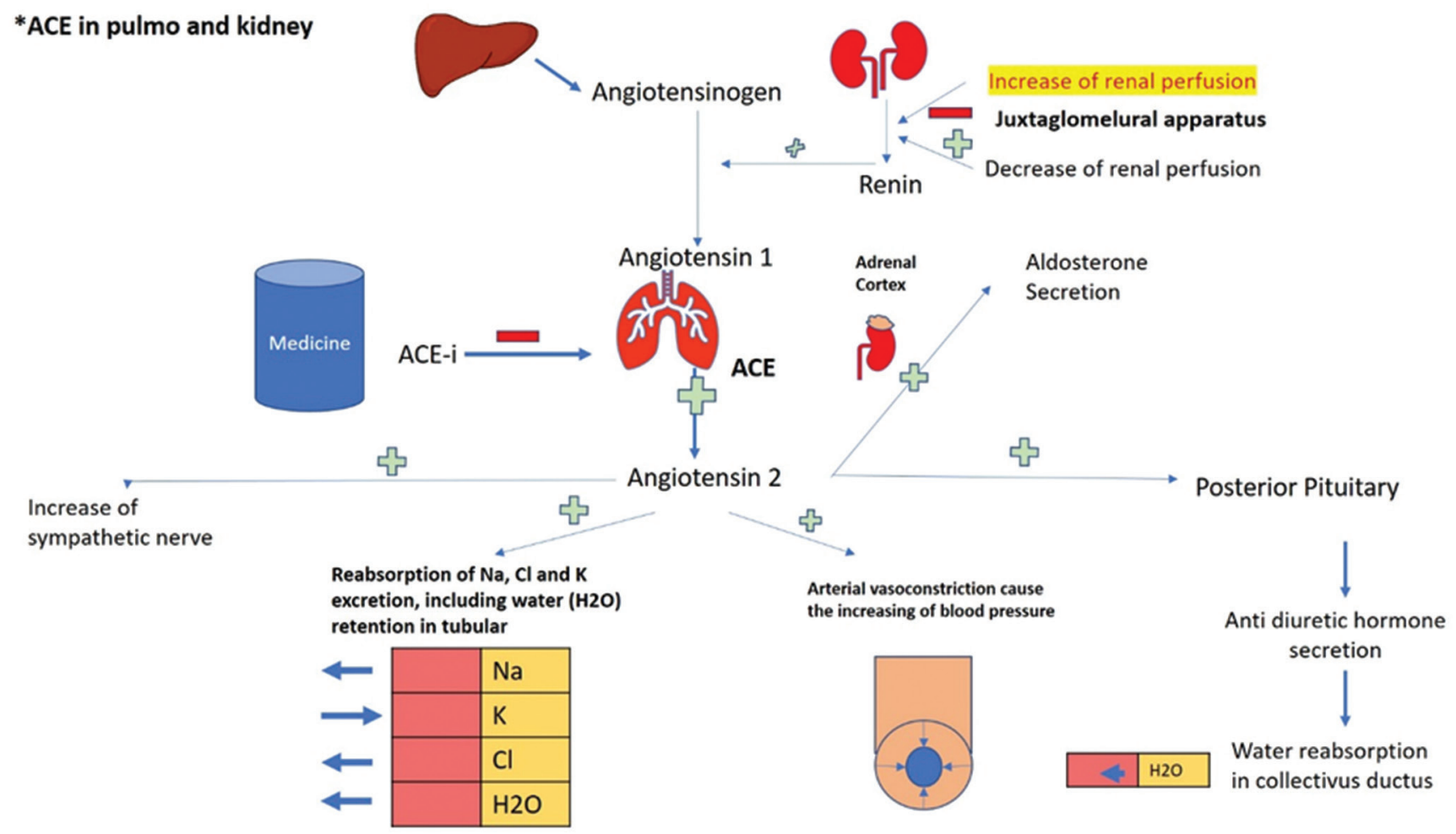

Figure 4: The renin angiotensin aldosterone system pathway. ACE=Angiotensin-converting enzyme, ACE-i=Angiotensin-converting enzyme inhibitor 
diverge depending on the situation. Furthermore, the ESC guidelines on managing hypertension during the pandemic state that discontinuing $A C E-i / A R B$ is not advised [6].

ACE is also found in the proximal tubule and glomerulus of the kidney. More so, an increase in its amount results in vasoconstriction of the renal vasculature, affecting fluid retention and inflammation of the renal vasculature and causes an increase in blood pressure. Therefore, hypertensive patients with kidney disease are given ACE-I to help lower blood pressure by decreasing vasoconstriction, water retention, salt intake, cell proliferation, and reactive oxygen stress [22]. Angiotensin-converting enzyme inhibitors are used to stop the rise in the levels of ACE.

Subsequently, the ratio of COVID-19 deaths caused by ACE-i and ARBs is lower than in patients who do not take ACE-i or ARBs. Other studies have found no differences in disease progression or risk of death while in the hospital. However, the use of ACE-i and $A R B s$ throughout the pandemic in response to severe COVID-19 has been contradictory. Still, most experts do not suggest stopping these medications after long-term use, especially at this time [23]. Furthermore, there were no differences in comorbidities associated with hypertension or length of hospital stay between ACE-i/ARB and non-ACE-i/ ARB patients [24].

\section{Conclusion}

Conclusively, there are still debates about the risk of COVID-19 disease associated with the treatment of hypertension using RAAS inhibitors such as ACE-i or ARBs. Furthermore, stopping treatment has negative effects and complications for people with hypertension and COVID-19. However, the clinician's discretion is required to determine whether ACE-i and ARB treatment should be continued or discontinued in the development of existing studies.

\section{Acknowledgments}

The Division of Nephrology and Hypertension, Department of Internal Medicine, and the Faculty of Medicine, Universitas Lambung Mangkurat, and Ulin Hospital, Banjarmasin, Indonesia, provided support for this development study.

\section{References}

1. World Health Organization. Subject in Focus: Origin of the Severe Acute Respiratory Syndrome Coronavirus-2 (SARSCoV-2), the Virus Causing COVID-19. Geneva: World Health Organization; 2021. Available from: https://www.who.int/docs/ default-source/coronaviruse/situation-reports/20200423-sitrep94-covid-19.pdf [Last accessed on 2021 Jul 26].

2. World Health Organization. Novel Corona Disease NEWS Situation Report 12. Geneva: World Health Organization; 2021. Available from: https://www.cdn.who.int/media/docs/defaultsource/searo/indonesia/covid19/external-situation-report64_21-july-2021.pdf?sfvrsn=e9aec4fa_5 [Last accessed on 2021 Jul 26].

3. South AM, Diz DI, Chappell MC. COVID-19, ACE2, and the cardiovascular consequences. Am J Physiol Heart Circ Physiol. 2020;318(5):H1084-90. https://doi.org/10.1152/ ajpheart.00217.2020

PMid:32228252

4. Gao C, Cai Y, Zhang K, Zhou L, Zhang Y, Zhang X, et al Association of hypertension and antihypertensive treatment with COVID-19 mortality: A retrospective observational study. Eur Heart J. 2020;41(22):2058-66. https://doi.org/10.1093/eurheartj/ ehaa433

PMid:32498076

5. Unger T, Borghi C, Charchar F, Khan NA, Poulter NR, Prabhakaran D, et al. International society of hypertension global hypertension practice guidelines. Hypertension. 2020;75(6)1334- 57. https://doi.org/10.1161/ HYPERTENSIONAHA.120.15026

PMid:32370572

6. European Society of Cardiology. Hypertension and COVID-19; 2020. Available from: https://www.escardio.org/education/covid19-and-cardiology/esc-covid-19-guidance [Last accessed on 2020 Jun 16]

7. Yang G, Tan Z, Zhou L, Yang M, Peng L, Liu J, et al. Angiotensin II Receptor Blockers and Angiotensin-Converting Enzyme Inhibitors Usage is Associated with Improved Inflammatory Status and Clinical Outcomes in COVID-19 Patients with Hypertension, MedRxiv; 2020

8. Mancia G, Rea F, Ludergnani M, Apolone G, Corrao G. Reninangiotensin-aldosterone system blockers and the risk of COVID- 19. N Engl J Med. 2020;382(25):2431-40.

9. Muneer K, Nair A. Angiotensin-converting enzyme inhibitors and receptor blockers in heart failure and chronic kidney diseasedemystifying controversies. Indian Heart J. 2017;69(3):371-4. https://doi.org/10.1016/j.ihj.2016.08.007 PMid:28648436

10. Rudiansyah M, Nur'amin HW, Nugrahaningsih DA, Bandiara R, Roesli RM. COVID-19: Drug development and kidney related problems. Syst Rev Pharm. 2020;11(7):106-12.

11. Rudiansyah M, Nur'amin HW, Lubis L, Bandiera R, Roesli RM, Rachmadi D. COVID-19 and kidney diseases in Indonesia. Syst Rev Pharm. 2020;11(7):435-42.

12. Jang $F$, Yang J, Zhang $Y$, Dong $M$, Wang $S$, Zhang $Q$, et al. Angiotensin-converting enzyme 2 and angiotensin 1-7: Novel therapeutic targets. Nat Rev Cardiol. 2014;11(7):413-26. https:// doi.org/10.1038/nrcardio.2014.59 PMid:24776703

13. Lu J, Sun PD. High affinity binding of SARS-CoV-2 spike protein enhances ACE2 carboxypeptidase activity. bioRxiv 2020;2020:182659. https://doi.org/10.1101/2020.07.01.182659 PMid:32637947 
14. Heurich A, Hofmann-Winkler H, Gierer S, Liepold T, Jahn O, Pöhlmann S. TMPRSS2 and ADAM17 cleave ACE2 differentially and only proteolysis by TMPRSS2 augments entry driven by the severe acute respiratory syndrome coronavirus spike protein. J Virol. 2014;88(2):1293-307. https://doi.org/10.1128/JVI.02202-13 PMid:24227843

15. Simões e Silva AC, Silveira KD, Ferreira AJ, Teixeira MM. ACE2, angiotensin-(1-7) and Mas receptor axis in inflammation and fibrosis. Br J Pharmacol. 2013;169(3):477-92. https://doi. org/10.1111/bph.12159

PMid:23488800

16. Kuba K, Imai $Y$, Rao S, Jiang $C$, Penninger JM. Lessons from SARS: Control of acute lung failure by the SARS receptor ACE2. J Mol Med (Berl). 2006;84(10):814-20. https://doi.org/10.1007/ s00109-006-0094-9 PMid:16988814

17. Jia, H. Pulmonary angiotensin-converting enzyme 2 (ACE2) and inflammatory lung disease. Shock. 2016;46(3):239-48. https:// doi.org/10.1097/SHK.0000000000000633

PMid:27082314

18. Tignanelli CJ, Ingraham NE, Sparks MA, Reilkoff R, Bezdicek T, Benson B, et al. Antihypertensive drugs and risk of COVID-19? Lancet Respir Med. 2020;8(5):e30-1. https://doi.org/10.1016/ S2213-2600(20)30153-3

PMid:32222166

19. Goyal A, Cusick AS, Thielemier B. ACE inhibitors. In: StatPearls. Treasure Island, FL: StatPearls Publishing; 2020.
20. Inciardi RM, Lupi L, Zaccone G, Italia L, Raffo M, Tomasoni D, et al. Cardiac involvement in a patient with Coronavirus disease 2019 (COVID-19). JAMA Cardiol. 2020;5(7):819-24. https://doi. org/10.1001/jamacardio.2020.1096

PMid:32219357

21. Cancarevic I, Malik BH. SARS-CoV-2 (COVID 19) infection in hypertensive patients and in patients with cardiac disease. Cureus. 2020;12(6):e8557. https://doi.org/10.7759/cureus.8557 PMid:32670694

22. Imai $Y$, Kuba K, Rao S. Angiotensin-converting enzyme 2 protects from severe acute lung failure. Nature. 2005;436(7047):112-6. https://doi.org/10.1038/nature03712 PMid:16001071

23. Zhang P, Zhu L, Cai J, Lei F, Qin JJ, Xie J, et al. Association of inpatient use of angiotensin-converting enzyme inhibitors and angiotensin II receptor blockers with mortality among patients with hypertension hospitalized with COVID-19. Circ Res. 2020;126(12):1671-81. https://doi.org/10.1161/ CIRCRESAHA.120.317134 PMid:32302265

24. Li J, Wang X, Chen J, Zhang H, Deng A. Association of reninangiotensin system inhibitors with severity or risk of death in patients with hypertension hospitalized for Coronavirus disease 2019 (COVID-19) infection in Wuhan, China. JAMA Cardiol. 2020;5(7):825-30. https://doi.org/10.1001/ jamacardio.2020.1624

PMid:32324209 